\title{
Characterization of F- and Al-codoped ZnO Transparent Conducting Thin Film prepared by Sol-Gel Spin Coating Method
}

\author{
Gil Mo Nam and Myoung Seok Kwon ${ }^{\dagger}$ \\ Department of Materials Science and Engineering, University of Seoul, Seoul 02504, Korea \\ (Received February 3, 2016; Revised March 11, March 28, 2016; Accepted March 29, 2016)
}

\begin{abstract}
$\mathrm{ZnO}$ thin film co-doped with $\mathrm{F}$ and $\mathrm{Al}$ was prepared on a glass substrate via simple non-alkoxide sol-gel spin coating. For a fixed $\mathrm{F}$ concentration, the addition of $\mathrm{Al}$ co-dopant was shown to reduce the resistivity mainly due to an increase in electrical carrier density compared with $\mathrm{ZnO}$ doped with $\mathrm{F}$ only, especially after the second post-heat-treatment in a reducing environment. There was no effective positive contribution to the reduction in resistivity due to the mobility enhancement by the addition of $\mathrm{Al}$ co-dopant. Optical transmittance of the $\mathrm{ZnO}$ thin film co-doped with $\mathrm{F}$ and $\mathrm{Al}$ in the visible light domain was shown to be higher than that of the $\mathrm{ZnO}$ thin film doped with $\mathrm{F}$ only.
\end{abstract}

Key words : Sol-gel, ZnO, Co-doping, Transparent conducting film, Spin-coating

\section{Introduction}

M ain interest item for the present study among various applications of doped $\mathrm{ZnO}$ thin films is the application of transparent conducting thin films in the flat panel display area. For flat panel display panels such as flat display panel and touch screen panel, etc. use of the transparent conducting films is essential, and the latter have been massproduced thus far with emphasis on ITO thin film containing In. ${ }^{1,2)}$ From the aspect of next-generation fundamental studies, transparent conducting oxide films for substitution of ITO have been widely studied, which do not contain the In element subjected to unstable supply and great price variations. Such transparent conducting thin films essentially require a low resistivity and a high optical transmittance in the visible light band. ${ }^{1-3)}$

The method widely studied as a preparation method for doped $\mathrm{ZnO}$ thin films is a physical vapor deposition (PVD) method such as sputtering. ${ }^{2-3)}$ In comparison with this, the sol-gel method ${ }^{4-7)}$ has advantages as a fundamental study method for the search of material systems, although its resistivity characteristics are rather poor. Namely, the advantageous features include that manufacturing equipment is inexpensive and simple, not only host composition but also types and contents of the added doping elements can be flexibly varied, and material synthesis begins in a homogeneous solution state at a molecular level. The followup crystallization heat treatment to finally obtain a crystallized thin film is also possible at a relatively low tempera-

'Corresponding author: Myoung Seok Kwon

E-mail : mskwon@uos.ac.kr

Tel : +82-2-6490-2411 Fax : +82-2-6490-2404 ture. Additional advantages include the fact that thin films can be formed on diversified substrates including a glass substrate. ${ }^{4-7)}$

In the studies on preparation of doped $\mathrm{ZnO}$ thin films by the sol-gel method, $\mathrm{Al}, \mathrm{Ga}$, In, etc. are being studied as doping elements. ${ }^{4-7)}$ As a thin-film coating method onto substrates, the method of dip coating or spin coating is being adopted. In the previous articles by the present authors, studies on spin coating of $\mathrm{ZnO}$ thin films by the sol-gel method have been reported, where the results concerning single dopants such as $\mathrm{Ga}, \mathrm{Al}$, and $\mathrm{F}$, etc. were reported in order. $^{8-10)}$ To form the doped $\mathrm{ZnO}$ thin films for application of a transparent conducting thin film, other study groups employed metal alkoxides. Unlike the latter, the present study group has adopted a zinc acetic compound which is easy to handle and of a low cost as the sol-gel precursor for $\mathrm{Zn}$. Ga and $\mathrm{Al}$ as a doping element were aimed at substitution of $\mathrm{Zn}$ ions, ${ }^{8,9)}$ while $\mathrm{F}$ doping was used for substitution of O ions. ${ }^{10)}$

The purpose of this article is to prepare $\mathrm{ZnO}$ thin films on glass substrates by co-doping of a small amount of $\mathrm{Al}$ along with $\mathrm{F}$ doping of an optimum concentration obtained in the previous study ${ }^{10)}$ as the basis, and to evaluate the characteristics thereof. Namely, after fixing the F doping content to be constant, microstructures along with changes in electrical and optical properties in the thin film were evaluated following preparation of $\mathrm{ZnO}$ thin films with a variation in the added amounts of $\mathrm{Al}$ as a co-doping element.

\section{Experimental Procedure}

$\mathrm{ZnO}$ thin films co-doped with $\mathrm{F}$ and $\mathrm{Al}$ by sol-gel spin coating were prepared on glass substrates. The present study experiments were performed on the basis of the sol-gel spin 
coating method reported by the present authors in the previous articles. ${ }^{8-10)}$ As the sol for $\mathrm{ZnO}$ thin film coating, zinc acetate dihydrate $\left(\mathrm{Zn}\left(\mathrm{OCOCH}_{3}\right) \cdot 2 \mathrm{H}_{2} \mathrm{O}\right)$ was selected as a starting material. The zinc acetate compound is a supply source for $\mathrm{ZnO}$ as a type of compounds, and has advantages of being stable at room temperature and of having a low cost. Also, 2-methoxyethanol with a high boiling point was selected as the solvent so that volatilization occurred slowly during spin coating as well as heat treatment process and compatibility of thin films was realized. Since solubility of the zinc acetate compound used as a solute in the 2methoxyethanol as a solvent is basically low, an adding method for the molar ratio to $\mathrm{Zn}$ acetate to be $1: 1$ was employed by using monoethanolamine (MEA) as a stabilizing agent. As the starting materials for $\mathrm{F}$ and $\mathrm{Al}$ used as dopants, ammonium fluoride and aluminium nitrate enneahydrate were selected.

After mixing 2-methoxyethanol and MEA at room temperature, the mixture was agitated on a hot plate at about $70^{\circ} \mathrm{C}$ for 90 minutes, and zinc acetate dihydrate was added to obtain $0.75 \mathrm{M}$. As the co-dopants, ammonium fluoride and ammonium nitrate were added to the mixed solution. After the final sol solution with preparation completed is aged for $48 \mathrm{~h}$, the doped $\mathrm{ZnO}$ thin films were prepared on glass substrates using a spin coater.

As a substrate for formation of the thin film, substrates with $250 \AA$ of $\mathrm{SiO}_{2}$ vapor deposited onto soda lime glass were used. The $\mathrm{SiO}_{2}$ glass substrates were ultrasonically cleaned in distilled water to remove organics and foreign objects from the surface. Then, dust on the substrates was blown off by using a nitrogen gun, followed by drying at $80^{\circ} \mathrm{C}$ for 30 minutes. The sol solution prepared earlier was dripped onto the substrate for wetting for 10 seconds, and rotated at a speed of $3000 \mathrm{rpm}$ for 30 seconds. From the coated thin films, organic solvent remaining on thin films was removed through pre-heat-treatment in air atmosphere at $350^{\circ} \mathrm{C}$ for 10 minutes. To obtain thin films of a sufficient thickness, the above processes were repeated for a few times. Finally, for realization of crystallization in $\mathrm{ZnO}$ thin films, the 1st post-heat-treatment was performed in the air atmosphere at $500 \sim 600^{\circ} \mathrm{C}$. The subsequent 2 nd post-heattreatment was performed in the hydrogen reduction atmosphere $\left(5 \% \mathrm{H}_{2}-95 \% \mathrm{~N}_{2}\right)$ to induce electrical activation and property improvement for the doped $\mathrm{ZnO}$ thin films.

By using X-ray diffraction (XRD, D8 Advanced X-ray, Bruker Axs), crystallinity and preferred orientation, etc. of the doped $\mathrm{ZnO}$ thin films were investigated. Surface shapes and particle sizes of the doped $\mathrm{ZnO}$ thin films were observed by using Field Emission Scanning Electron Microscope (FESEM, S-4300, Hitachi, Japan). Electrical properties of the doped $\mathrm{ZnO}$ thin films were measured by using Hall Effect measurement System (HMS-3000, Ecopia). Electrical properties such as resistivity, carrier concentration, Hall mobility, etc. were measured and extracted. And, for optical properties evaluation as a transparent conducting thin film for flat panel display, optical transmittance in the visible light domain of $400 \sim 800 \mathrm{~nm}$ in wavelength was measured by using UV-visible spectrometer (UV-3150. Shimazu, Japan).

\section{Results and Discussion}

The present authors have reported the results of preparation by sol-gel method with addition of $\mathrm{F}$ as the single dopant to improve electrical conductivity and material property characteristics of $\mathrm{ZnO}$ in the previous study. ${ }^{10)}$ In the current study, experiments were conducted while the added concentrations of a small amount of $\mathrm{Al}$ were varied with the doping composition of $\mathrm{F}$ fixed at 2.0 at. \% which showed the most excellent electrical properties in the previous study.

Figure 1 shows the results of XRD pattern for the $\mathrm{ZnO}$ thin films co-doped with 2.0 at. \% of $\mathrm{F}$ and $0 \sim 0.8$ at.\% of $\mathrm{Al}$. The thin films were samples with the 2 nd post heat treatment in the hydrogen reduction atmosphere $\left(5 \% \mathrm{H}_{2}-95 \%\right.$ $\mathrm{N}_{2}$ ) at $450^{\circ} \mathrm{C}$ for 30 minutes after the 1 st post heat treatment in the air atmosphere at $500^{\circ} \mathrm{C}$ for $1 \mathrm{~h}$. For comparison of diffraction results, the results for the $\mathrm{ZnO}$ thin films with no doping of $\mathrm{F}$ and $\mathrm{Al}$ are listed alongside. The $\mathrm{ZnO}$ thin films without a dopant and the doped thin films commonly exhibit diffraction peaks corresponding to (002) face of the hexagonal $\mathrm{ZnO}$ crystal structure. The result is implied where the $\mathrm{ZnO}$ thin film is preferentially oriented along the (002) face or the c-axis direction. Peak intensity distribution

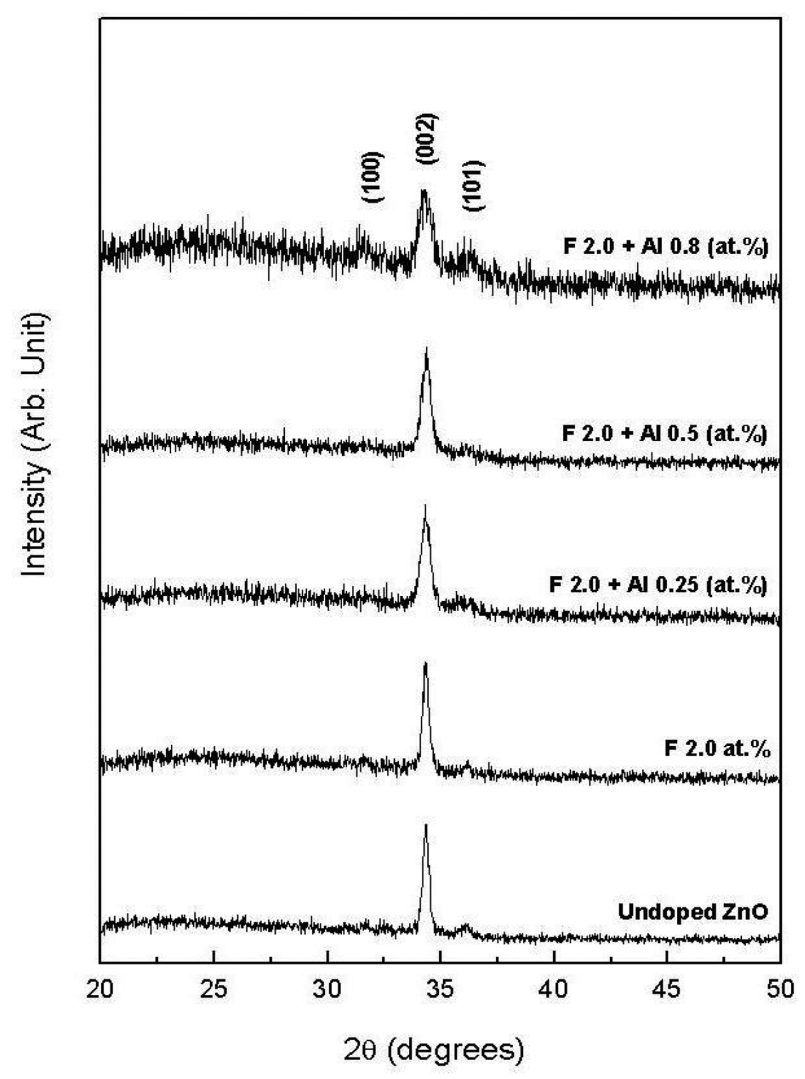

Fig. 1. XRD patterns of the co-doped $\mathrm{ZnO}$ films (F 0 or 2 at.\%+ Al $0 \sim 0.8$ at.\%). 
for the thin film samples doped with $\mathrm{F}$ only and the codoped thin film samples did not show a large difference. In the samples with addition of 0.8 at.\% of $\mathrm{Al}$ as a co-doping element, the peak intensity was somewhat reduced, and the weak peaks of (100) face and (101) face were observed.

Within the experimental composition range of the present study, the undoped $\mathrm{ZnO}$ thin films, the $\mathrm{ZnO}$ thin films doped with $\mathrm{F}$ only, and the $\mathrm{ZnO}$ thin films co-doped with $\mathrm{F}$ and $\mathrm{Al}$ are considered to show the preferred orientation mainly along c-axis. In addition, when the concentrations of co-doped $\mathrm{Al}$ were increased, it was shown that such preferred orientation could be reduced.

Figure 2 shows the measured results of resistivity for the co-doped $\mathrm{ZnO}$ thin films where $\mathrm{Al}$ concentrations were varied between 0 at.\% 0.8 at.\% after $\mathrm{F}$ concentration was maintained to be constant at 2 at.\%. The thin films were prepared by the 1st post heat treatment in the air atmosphere at $500^{\circ} \mathrm{C}$ for $1 \mathrm{~h}$, followed by the 2 nd post heat treatment in the hydrogen reduction atmosphere $\left(5 \% \mathrm{H}_{2}-95 \% \mathrm{~N}_{2}\right)$ at $450^{\circ} \mathrm{C}$ for 30 minutes.

According to the previous study results by the authors, ${ }^{10)}$ the reduction effect of resistivity by the 2 nd heat treatment in the reducing atmosphere was not observed as compared with the results after the 1st post heat treatment in the air atmosphere, in the case of $\mathrm{ZnO}$ thin films doped with $\mathrm{F}$ only. On the contrary, the result of an increase in resistivity was exhibited after the 2 nd post heat treatment in the reducing atmosphere. ${ }^{10)}$ In addition, the resistivity when $\mathrm{F}$ doping concentration was 2 at.\% was reported to be minimized commonly for both the measured values of resistivity after the 1 st post heat treatment and the results after the 2nd post heat treatment. ${ }^{10)}$ The minimum resistivity figure after the 1 st post heat treatment wad $5.62 \Omega \cdot \mathrm{cm}^{10)}$

As shown in Fig. 2, the thin films doped with 2 at.\% of $F$ and those doped with 0.5 at.\% of $\mathrm{Al}$ showed a resistivity value of $7.4 \times 10^{-2} \Omega \mathrm{cm}$ which was the minimum value after the 2 nd post heat treatment in the reducing atmosphere. Therefore, as compared with the previous study result by the authors for the $\mathrm{ZnO}$ thin films doped with 2 at.\% of $\mathrm{F}$

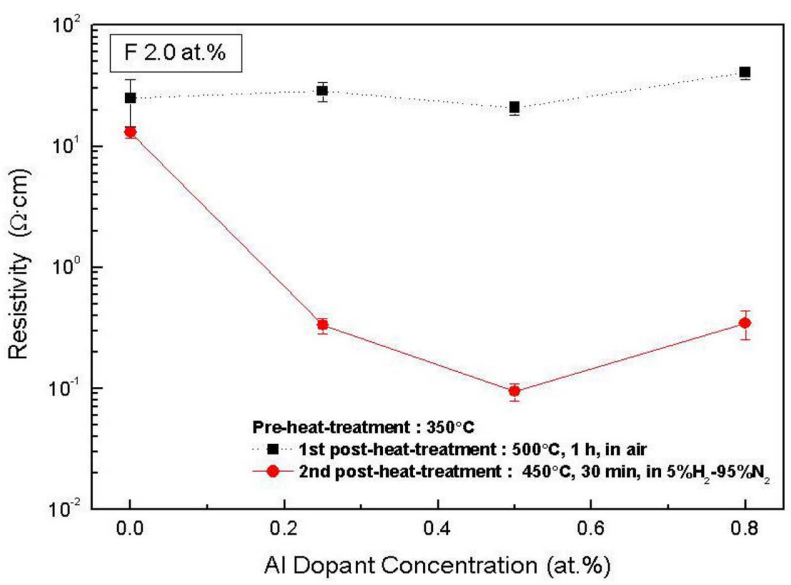

Fig. 2. Resistivity of the co-doped $\mathrm{ZnO}$ films $(\mathrm{F} 2$ at.\% $+\mathrm{Al}$ $0 \sim 0.8$ at.\%) only, the improved characteristics were obtained where the resistivity was reduced by about 2 orders of magnitude. The thin films co-doped with $\mathrm{F}$ and $\mathrm{Al}$ showed the lowest resistivity characteristics when 0.5 at.\% of $\mathrm{Al}$ was added under the condition where $\mathrm{F}$ concentration was constant at 2 at.\%. Also, it represents the result of improvement by 1 order of magnitude compared with the resistivity value as the previous study result ${ }^{9)}$ where only $\mathrm{Al}$ was doped.

According to this experimental result, the result could be observed where the co-doping method with addition of $\mathrm{Al}$ and $\mathrm{F}$ induced a change in electrical properties for thin films unlike the cases of single doping with an individual element only. Also, the result of a marked reduction in resistivity values was obtained upon the 2 nd post heat treatment in the hydrogen reduction atmosphere $\left(5 \% \mathrm{H}_{2}-95 \% \mathrm{~N}_{2}\right)$ after co-doping with $\mathrm{F}$ and $\mathrm{Al}$, as compared with only the 1st post heat treatment in the air atmosphere.

Figure 3 shows a graph for carrier concentrations and Hall mobilities of the $\mathrm{ZnO}$ thin films prepared with a change in the doped amounts of $\mathrm{Al}$ while the doped amount of $\mathrm{F}$ was maintained to be constant at 2 at.\%. The thin films were prepared through the 1st post heat treatment in the air atmosphere at $500^{\circ} \mathrm{C}$ for $1 \mathrm{~h}$, followed by the $2 \mathrm{nd}$ post heat treatment in the hydrogen reduction atmosphere $(5 \%$ $\mathrm{H}_{2}-95 \% \mathrm{~N}_{2}$ ) at $450^{\circ} \mathrm{C}$ for 30 minutes. For the composition where the co-doped amount of $\mathrm{Al}$ showing the minimum resistivity in Fig. 2 as the previous resistivity result was made to be 0.5 at. $\%$, the carrier concentration and the mobility showed the values of $5.59 \times 10^{19} \mathrm{~cm}^{-3}$ and $1.12 \mathrm{~cm}^{2} /$ $\mathrm{V} \cdot \mathrm{s}$, respectively. The carrier concentration for the sample where doped amounts of $\mathrm{Al}$ were varied with the amount of $\mathrm{F}$ fixed at 2 at.\% showed the lowest figure when $\mathrm{Al}$ was not doped, and showed the maximum value of $7.37 \times 10^{19} \mathrm{~cm}^{-3}$ when 0.25 at.\% of $\mathrm{Al}$ was added. Afterward, the carrier concentration was not increased further even if the added concentrations of $\mathrm{Al}$ were increased, rather showing the result of a slight reduction. When $\mathrm{Al}$ was not added after $\mathrm{F}$ was fixed at 2 at.\%, Hall mobility showed the maximum value of $6.61 \mathrm{~cm}^{2} / \mathrm{V} \cdot \mathrm{s}$, while the minimum value was observed when

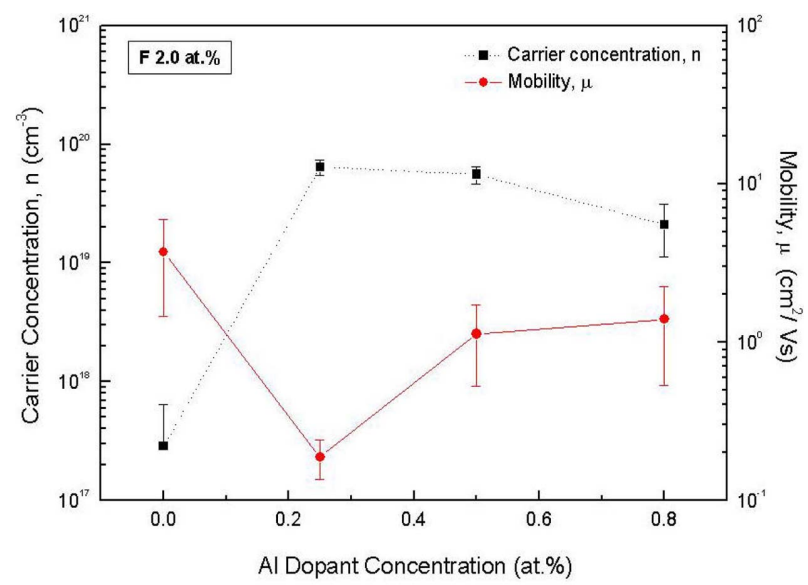

Fig. 3. Carrier concentration and mobility of the co-doped $\mathrm{ZnO}$ films (F 2 at.\% + $\mathrm{Al} 0 \sim 0.8$ at.\%). 
0.25 at. $\%$ of $\mathrm{Al}$ was added. When the added amounts of $\mathrm{Al}$ were more than 0.25 at.\%, the mobility was increased again as the $\mathrm{Al}$ concentrations were increased. When $\mathrm{Al}$ is codoped with the $\mathrm{F}$ concentration being fixed, the carrier concentrations were increased by about 2 orders of magnitude. Carrier concentrations did not show a tendency of being correspondingly increased as the $\mathrm{Al}$ concentrations were increased when $\mathrm{Al}$ existed as a co-doping element. Carrier concentrations rather showed the result of being reduced when the concentrations of the co-dopant $\mathrm{Al}$ continued to be increased. Also, under the condition where the carrier concentration showed the maximum value, the mobility exhibited the minimum figure, and showed an increase as the carrier concentrations were reduced. As a result of adding $\mathrm{Al}$ as a co-dopant with the $\mathrm{F}$ concentration maintained to be constant, the overall tendency was an increase in the carrier concentrations by about 2 orders of magnitude with addition of a small amount of $\mathrm{Al}$, while the increasing effect of mobilities are considered not to exist. In the case of mobility, it rather showed the result of reduced figures as the digit number of the carrier concentration was increased. Consequently, the macroscopic reduction of resistivity(improvement of electrical conductivity) shown earlier in Fig. 2 is considered to be most largely dependent on the increase in carrier concentrations induced by addition of the co-dopant $\mathrm{Al}$ to the fixed $\mathrm{F}$ concentration.

Figure 4 shows the FE-SEM pictures of shapes of thin film surfaces observed for the undoped $\mathrm{ZnO}$ thin films, the thin films doped with 2 at.\% of $\mathrm{F}$ only, the thin films doped with 0.5 at.\% of $\mathrm{Al}$ only, and the thin films doped with 2 at.\% of $\mathrm{F}$ and co-doped with 0.5 at.\% of $\mathrm{Al}$. The thin films were subjected to the 1st post heat treatment in the air atmosphere at $500^{\circ} \mathrm{C}$ for $1 \mathrm{~h}$, followed by the $2 \mathrm{nd}$ post heat treatment in the hydrogen reduction atmosphere $\left(5 \% \mathrm{H}_{2}-95 \% \mathrm{~N}_{2}\right)$ at $450^{\circ} \mathrm{C}$ for 30 minutes. Surface shapes for the undoped $\mathrm{ZnO}$ thin films and the thin films with 2 at.\% of $\mathrm{F}$ added were observed not to have a large difference. In contrast, particle sizes can be observed to be remarkably reduced in the thin

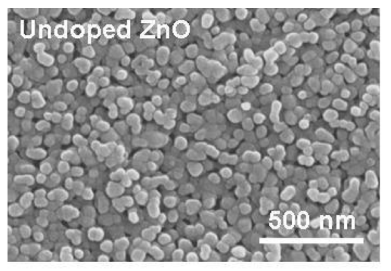

(a)

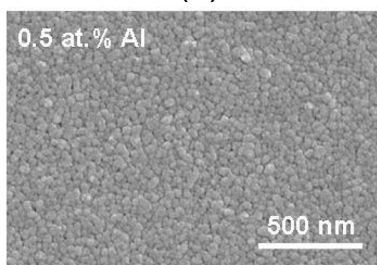

(c)

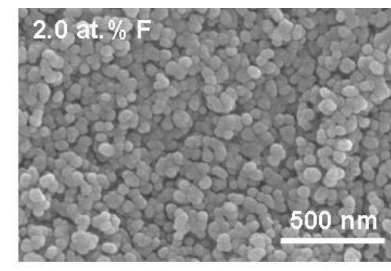

(b)

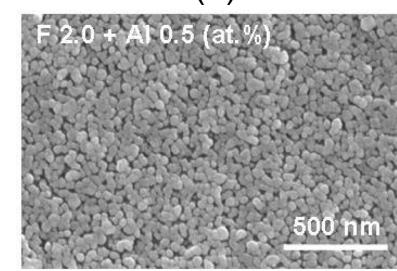

(d)
Fig. 4. FE-SEM micrographs of the surface of the co-doped $\mathrm{ZnO}$ films (F 0 or 2 at.\% + $\mathrm{Al} 0.5$ at.\%). films with addition of 0.5 at.\% of $\mathrm{Al}$ only. Crystal sizes of thin films with co-doping of 2 at.\% of $\mathrm{F}$ and 0.5 at.\% of $\mathrm{Al}$ are considered to be between the crystal size of the thin films with single doping of $\mathrm{F}$ only and that of the thin films with single doping of $\mathrm{Al}$ only. Relatively fewer pores were observed for the co-doped thin films as compared with the undoped films and the films having single doping of $\mathrm{F}$ only.

Figure 5 shows a graph for optical transmittance in the visible light domain $(400 \sim 800 \mathrm{~nm}$ ) of the $\mathrm{ZnO}$ thin films prepared by doping with a given concentration of $\mathrm{F}$ and varying concentrations of the co-doped $\mathrm{Al}$. The thin films prepared by sol-gel method were subjected to the 1st post heat treatment in the air atmosphere at $500^{\circ} \mathrm{C}$ for $1 \mathrm{~h}$, followed by the hydrogen reduction heat treatment in the hydrogen reduction atmosphere $\left(5 \% \mathrm{H}_{2}-95 \% \mathrm{~N}_{2}\right)$ at $450^{\circ} \mathrm{C}$ for 30 minutes. Thickness of the thin films co-doped with 2 at. $\%$ of $\mathrm{F}$ and 0.25 at.\% of $\mathrm{Al}$ was $295 \mathrm{~nm}$, and an excellent optical transmittance of about $96 \%$ was exhibited. Thickness range for the $\mathrm{ZnO}$ thin films co-doped with $\mathrm{F}$ and $\mathrm{Al}$ was $290 \sim 320 \mathrm{~nm}$, and an optical transmittance of about $92 \sim 96 \%$ was observed in the visible light domain. Also, within the concentration variation range of the present experiments the $\mathrm{ZnO}$ thin films with additional co-doping of $\mathrm{Al}$ showed rather the improved results in optical transmittance across the entire range in comparison with the thin films with single doping of $\mathrm{F}$ only.

Therefore, in the doped $\mathrm{ZnO}$ thin films based on $\mathrm{F}$, interesting results could be obtained where $\mathrm{Al}$ added as a co-doping element contributed to the improvement of optical transmittance. Based on the XRD diffraction results of Fig. 1, the results could also be observed where the preferred orientation observed with a continued increase in the contents of added $\mathrm{Al}$ began to be reduced. Macroscopic aspect of resistivity as well as the variation aspects of microscopic carrier concentration and mobility which were observed when the contents of added $\mathrm{Al}$ continued to be increased at a given $\mathrm{F}$ concentration are considered to suggest that the domain of optimum doping concentration exists within a given range.

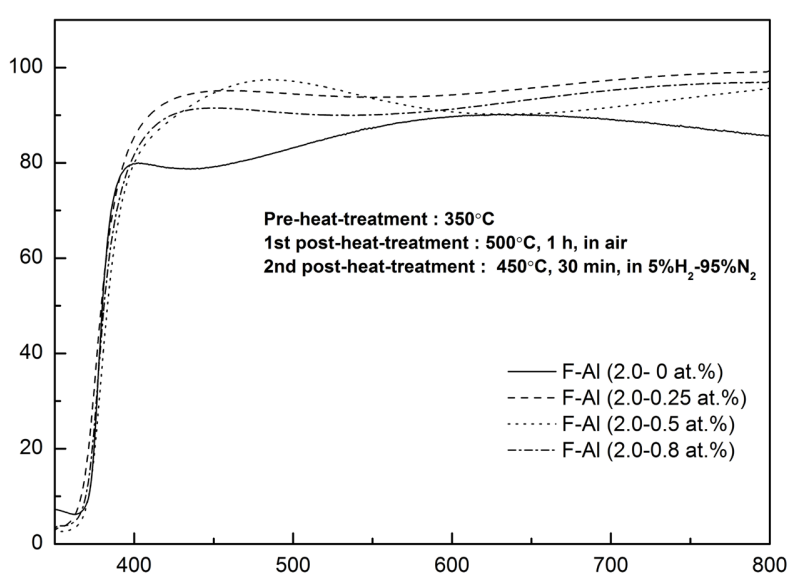

Fig. 5. Optical transmittance of the co-doped $\mathrm{ZnO}$ films ( $\mathrm{F}$ 2.0 at. $\%+\mathrm{Al}: 0.25,0.5,0.8$ at.\% of $\mathrm{F})$. 
In the aspect of particle sizes for the polycrystalline $\mathrm{ZnO}$ thin films obtained by the sol-gel method, the particle sizes of the undoped $\mathrm{ZnO}$ thin films and the $\mathrm{ZnO}$ thin films with single doping of $\mathrm{F}$ only tended to be larger than those of the thin films with single doping of $\mathrm{Al}$ only, and hence the particle sizes upon additional co-doping of a small amount of $\mathrm{Al}$ with $\mathrm{F}$ as the base could be observed to be larger in comparison with those for the polycrystals doped with $\mathrm{Al}$ only.

\section{Conclusions}

As compared with material properties of the $\mathrm{ZnO}$ thin films with single doping of $\mathrm{F}$ only, the $\mathrm{ZnO}$ thin films codoped with $\mathrm{F}$ and $\mathrm{Al}$ showed the results of reduction in resistivity by 2 orders of magnitude after undergoing the 2nd post heat treatment process in a reducing atmosphere. When the added amounts of $\mathrm{Al}$ are varied while the $\mathrm{F}$ concentration is fixed to be constant, the concentration range for $\mathrm{Al}$ addition minimizing resistivity is considered to exist, and the factors determining such macroscopic change in the resistivity are considered to mainly originate from the increase in carrier concentrations as a result of $\mathrm{Al}$ addition. In contrast, the reduction effect of resistivity due to an increase in mobilities is considered not to exist even if $\mathrm{Al}$ is added at a constant $\mathrm{F}$ concentration. In comparison with the $\mathrm{ZnO}$ thin films with single doping of $\mathrm{F}$ only, the $\mathrm{ZnO}$ thin films with co-doping of $\mathrm{F}$ and $\mathrm{Al}$ exhibited rather an improvement of optical transmittance in the visible light domain. Meanwhile, it has been observed that the crystallinity and the preferred orientation of the thin films as well as the particle sizes and the compactness of the polycrystals were affected according to the presence status and the contents of doped $\mathrm{F}$ and $\mathrm{Al}$.

\section{Acknowledgments}

This work was supported by the 2013 sabbatical year research grant of the University of Seoul.

\section{REFERENCES}

1. T. Minami, "New n-type Transparent Conducting Oxides," MRS Bull., 25 [8] 38-44 (2000).

2. D. C. Plain, H. Y. Yeom, and B. Yaglioglu, "Transparent Conducting Oxide Materials and Technology," pp. 79-98 in Flexible Flat Panel Displays Edited by G. P. Crawford, John Wiley \& Sons, Ltd, Singapore, 2005

3. G. J. Exarhos and X.-D. Zhou, "Discovery-Based Design of Transparent Conducting Oxide Films," Thin Solid Films, 515 [18] 7025-52 (2007).

4. Y.-S. Kim and W.-P. Tai, "Electrical and Optical Properties of Al-doped ZnO Thin Films by Sol-Gel Process," Appl. Surf. Sci., 253 [11] 4911-16 (2007)

5. A. Kurz, K. Brakecha, J. Puetz, and M. A. Aegerter, "Strategies for Novel Transparent Conducting Sol-Gel Oxide Coatings," Thin Solid Films, 502 [1-2] 212-18 (2006).

6. S. Mridha and D. Basak, "Effect of Thickness on the Structural, Electrical and Optical Properties of ZnO Films," Mater. Res. Bull., 42 [5] 875-82 (2007).

7. C.-S. Hong, H.-H. Park, J. Moon, and H. H. Park, "Effects of Metal (Al,Ga, and In)-Dopants and/or Ag-Nanoparticles on the Optical and Electrical Properties of $\mathrm{ZnO}$ Thin Films," Thin Solid Films, 515 [3] 957-60 (2006).

8. G. M. Nam and M. S. Kwon, " Transparent Conducting Gadoped ZnO Thin Film for Flat-Panel Displays with a SolGel Spin Coating," J. Inf. Disp., 9 [3] 8-11 (2008).

9. G. M. Nam and M. S. Kwon, "Al-Doped $\mathrm{ZnO}$ via Sol-Gel Spin-Coating as a Transparent Conducting Thin Film," J. Inf. Disp., 10 [1] 24-7 (2009).

10. G. M. Nam and M. S. Kwon, "F-Doped ZnO by Sol-Gel Spin-Coating as a Transparent Conducting Thin Film," Electron. Mater. Lett., 7 [2] 127-31 (2011). 